\title{
A arte no ensino da Química: a linguagem que transforma
}

\author{
Art in the teaching of Chemistry: the language that transforms \\ El arte en la enseñanza de la Química: el lenguaje que transforma
}

Recebido: 22/09/2021 | Revisado: 29/09/2021 | Aceito: 13/10/2021 | Publicado: 15/10/2021

\author{
Emily Cristina Silva Sousa Ramos \\ ORCID: https://orcid.org/0000-0002-1380-1443 \\ Universidade Federal do Maranhão, Brasil \\ E-mail: m.lyramos@ufma.br \\ Cicero Wellington Brito Bezerra \\ ORCID: https://orcid.org/0000-0001-9058-9469 \\ Universidade Federal do Maranhão, Brasil \\ E-mail: cwb.bezerra@ufma.br
}

\begin{abstract}
Resumo
O modelo educacional tecnologicamente orientado, de caráter exclusivamente profissional, concebe o aluno apenas pelo seu viés cognitivo, e de modo parcial, com capacidade apenas para absorver conhecimentos e reproduzi-los sem expressão individual alguma. Tal modelo, mecânico e instintivo, priva o aluno da sua criatividade, limita o processo de apropriação cultural, impede o aluno de ser o sujeito da sua construção e encurrala o professor na condição de mero explicador de conteúdo. Não haverá beleza no fazer científico? Não causa encantamento o descobrir que, na fornalha de uma locomotiva, ao acender dos carvões de pedra, brilham raios de sol extintos há milênios? $\mathrm{O}$ ato de educar não é um ato de comunicação? A Arte não engloba todas as formas de expressão humana? Como dissociar, então, Ciência e Arte? Para superar equívocos de uma educação unilateral, cognitiva, pautada apenas no determinismo e na causalidade, é necessário repensar a dualidade Ciência-Artes, razão-subjetividade. Este artigo, através de uma análise documental, qualitativa, descritiva e exploratória, empregando recursos de análise de conteúdo (Bardin, 2016), visita e discute alguns documentos oficiais que orientam a educação brasileira, Lei de Diretrizes e Bases da Educação Nacional e Base Nacional Comum Curricular, acentuando aspectos relevantes do diálogo Ciência e Arte para viabilizar uma educação integral, que contemple o aluno em sua completude, tornando-o mais autônomo, consciente, autoconfiante, reflexivo e participativo.
\end{abstract}

Palavras-chave: Ensino de Ciências; Arte; LDB; BNCC; Análise de conteúdo; Abordagem cultural.

\begin{abstract}
The technologically oriented educational model, of an exclusively professional nature, conceives the student only through their cognitive bias, and partially, with the capacity only to absorb knowledge and reproduce it without any individual expression. Such a mechanical and instinctive model deprives the student of their creativity, limits the process of cultural appropriation, prevents the student from being the subject of their own construction and traps the teacher as a mere content explainer. Is there no beauty in making science? Is it not enchanting to discover that, in the furnace of a locomotive, when the coals of stone are lit, sunbeams that have been extinct for millennia are shining? Is educating not an act of communication? Doesn't Art encompass all forms of human expression? How, then, can one dissociate Science and Art? To overcome the mistakes of a unilateral, cognitive education, based only on determinism and causality, it is necessary to rethink the dualities of Science-Arts and reason-subjectivity. This article, through a documental, qualitative, descriptive and exploratory analysis, using content analysis resources (Bardin, 2016), visits and discusses some official documents that guide Brazilian education, Law of Guidelines and Bases of National Education and Common National Curricular Base, emphasizing relevant aspects of the dialogue between Science and Art to enable a comprehensive education, which contemplates the student in its entirety, making them more autonomous, aware, self-confident, reflective and participatory.
\end{abstract}

Keywords: Science teaching; Art; LDB; BNCC; Content analysis; Cultural approach.

\section{Resumen}

El modelo educacional tecnológicamente orientado, de carácter exclusivamente profesional, concibe el alumno solamente por su tendencia cognitiva, y de forma parcial, con capacidad únicamente para absorber conocimientos y reproducirlos sin ninguna expresión individual. Dicho modelo, mecánico e instintivo, inhibe la creatividad del alumno, limita el proceso de apropiación cultural, impide al alumno de ser el sujeto de su construcción y cerca al profesor limitándolo a la condición de mero explicador de contenido. No existe belleza en el quehacer científico? No provoca un encanto el descubrir que, en el horno de una locomotora, al prender el carbón de piedra, brillan rayos de sol extinguidos hace milenios? Para superar equivocaciones de una educación apenas unilateral, cognitiva, pautada en el determinismo y en la casualidad, es necesario repensar la dualidad Ciencia-Artes, razón-subjetividad. Este artículo, por medio de un análisis de documentos, cualitativo, descriptivo y exploratorio, empleando recursos de análisis de 
contenido (Bardin, 2016), visita y discute algunos documentos oficiales que orientan la educación brasileña, Ley de Directrices y Bases de la Educación Nacional y Base nacional Común Curricular, acentuando aspectos relevantes del diálogo Ciencia y Arte para viabilizar una educación integral, que contemple al alumno en su totalidad, tornándolo más autónomo, consciente, autoconfiante, reflexivo y participativo.

Palabras clave: Enseñanza de Ciencias, Arte; LDB; BNCC; Análisis del contenido; Abordaje cultural.

\section{Introdução}

A arte é, antes de tudo, uma forma de conhecer, sentir, expressar e organizar a experiência humana. Em um sentido mais geral e platônico, a arte não se distingue da ciência (a arte do raciocínio) e significa o conjunto de regras capaz de dirigir qualquer atividade humana (Abbagnano, 2007). Algo próximo do termo técnica, empregado bastante hoje em dia. Mesmo para Aristóteles, quem reduziu o conceito de arte à esfera do possível (daquilo que é mutável), em oposição à esfera do necessário (no caso da ciência), daquilo que não encerra a possibilidade de ser diferente, a arte permanece como uma das maneiras através das quais se pode alcançar a verdade. Em sua concepção, a arte é a capacidade racional voltada para o criar, para o vir a ser; produtiva e criativa (Aristóteles, 2014).

Inconteste, como busca e expressão do humano, a arte sempre esteve e está presente nos movimentos de interpretação e de interação com o mundo. Fez e faz parte do processo de humanização e é capaz de acessar e ativar dimensões e competências humanas que outras formas de saber não as alcançariam. Acorre ao processo educacional, portanto, e dele é indiviso, por ser manifestação da própria racionalidade e fruto da inteligência. A arte, evidente, é parte da cultura humana, assim como outras variedades do saber (Silveira et al, 2020; Santos, 2009), entretanto, superando a perspectiva empíricopositivista ainda dominante no pensamento científico, a arte, por meio da imaginação e da intuição, alarga o horizonte da experiência sensível, desenvolvimento percepções, sensibilidade e criatividade. De acordo com Aranha e Martins (2009, p.420) "tanto o artista quanto o cientista trabalham intelectualmente a inspiração": formulam projetos, assumem previamente conceitos e, com suas ideias e sentimentos, perseguem os seus objetivos por meio de técnicas, estilos e materiais que lhe sejam mais adequados.

Neste sentido, bastante conhecida é a afirmação de Einstein sobre a imaginação dada em entrevista ao The Saturday Evening Post, em 1929, a de que ela é mais importante do que o próprio conhecimento. Enquanto este é limitado, aquela abraça o mundo inteiro, estimulando o progresso e fomentando a evolução, sendo um elemento presente e importante da pesquisa científica (Viereck, 1929). Gurgel e Pietrocola (2011), abordando o tema imaginação através do enfoque históricoepistemológico observaram que ela é função do pensamento e que além de buscar, também, apreender o real, está presente também em outras partes do trabalho científico, como na elaboração de procedimentos experimentais.

Desta forma, ciência e arte não são campos tão distintos e se ajustam quanto ao propósito da educabilidade do ser humano. Este trabalho tem como principal objetivo explorar os possíveis diálogos entre Ciência e a Arte no contexto escolar, notadamente pelo viés de documentos oficiais da área de ensino, através de uma leitura crítico-descritiva, destacando os pressupostos teóricos que fundamentam a associação entre esses dois campos do saber, discutindo possíveis diálogos e impactos na ação docente e na formação do aluno.

\section{Metodologia}

Esta é uma pesquisa documental e bibliográfica, de cunho qualitativo, de caráter exploratório e descritivo. A análise textual foi referenciada pela Análise de Conteúdo (AC) de Bardin (2016), que consiste em etapas de pré-análise, organização, análise e interpretação dos dados.

$\mathrm{Na}$ pré-análise foram realizadas leituras flutuantes com o objetivo de selecionar os documentos que abordassem possíveis concepções sobre ciência e artes para o ensino regular. O documento selecionado para a análise a posteriori foi a 
BNCC com consultas à LDBEN, considerando que ambos os documentos objetivam as normativas existentes e vigentes para a educação brasileira. O corpus da pesquisa foi composto por dois temas categóricos: Propósitos do ensino de Ciências na BNCC, e as Relações entre Ciências e Arte na BNCC. As hipóteses levantadas propõem analisar como a educação é entendida nesses documentos, qual a linguagem, as intenções e as possíveis interesses evidenciados na escrita? Quais concepções sobre ciência e artes discutidas no texto? Existe alguma relação entre esses campos do saber nos documentos analisados?

A Análise de Conteúdos (AC) é definida por Bardin (2016) como uma operação ou um conjunto de operações que visa representar o conteúdo de um documento sob uma perspectiva diferente da original, envolvendo técnicas de armazenamento de dados que facilita o acesso do observador ao máximo de informações extraídas do texto, essas informações disporão do máximo de pertinência para com os objetivos do estudo em questão, o que remete a tendência qualitativa da pesquisa.

O eixo analítico empregado foi o da Análise temática, que consiste na contagem dos temas presentes no texto para identificar, analisar, interpretar e relatar padrões temáticos a partir de dados qualitativos (Bardin, 2016).

\section{Resultados e Discussão}

\subsection{Arte e ciência em contemporização}

A arte surgiu com os primórdios da humanidade e se revelou desde suas primeiras ações, as pinturas rupestres, a criação da roda e as primeiras formas de trabalho, todas se fizeram por meio de conceitos artísticos para atender os interesses da humanidade. $\mathrm{O}$ homem criou a arte para melhorar sua sobrevivência no meio, expressar o que pensa divulgar suas crenças ou a de outros, para estimular e distrair, para explorar novas formas de olhar e interpretar objetos e cenas (Fischer, 1987). Historicamente o termo "arte" passou a ser utilizado popularmente somente a partir o século XIII, primeiramente na língua inglesa "art" derivando do termo raiz da palavra artem, de origem latina, cujo significado é "habilidade". Até o final do século XVIII, o termo foi utilizado em assuntos diversos da sociedade, tudo que era feito com destreza como a habilidade na matemática, na medicina ou na pesca com vara era considerado uma arte (Ferreira, 2010).

O conceito de arte não define categorias de coisas, mas um tipo de valor. A arte está ligada ao trabalho humano e suas técnicas mentais e operacionais são formas significantes às quais a consciência atribui significados. A história da arte não é uma história dos objetos, mas uma história dos juízos de valor acerca dos objetos e, por isso, ela é fundamental para compreender a sociedade. (Argan, p.23, 1994).

Nesse período histórico a maioria das ciências eram artes, a habilidade matemática, as habilidades médicas e habilidades alquimistas eram consideradas arte. Ao analisar a etimologia das artes liberais na Idade Média, Ferreira (2010) observou que a primeira parte do ensino universitário era formada pelas três disciplinas do trivium (gramática latina, lógica e retórica), seguidas pelas disciplinas do quadrivium (aritmética, geometria, música e astronomia - o conjunto dos quatro ramos do saber). Que constituíam as sete artes também conhecidas como artes liberais. Nota-se que nesse período os campos científico e artístico se complementavam, infelizmente não por muito tempo, a partir do século XV foram atribuídos a esses saberes conceitos, características e aplicações diferentes tal pensamento os mantiveram isolados em suas especialidades, como se não houvesse possibilidade de diálogo entre eles.

Ao longo dos anos, a arte e ciência foram se afastando cada vez mais e, no paradigma dominante, elas passaram a assumir características, linguagens, métodos, processos cognitivos e vinculações epistemológicas independentes, diferenciadas e, às vezes, também opostas. Como escreve Willians (2007), o crescimento da apreciação das obras estéticas, esculturais e arquitetônicas começa a fundamentar uma visão moderna de arte, nesse cenário a arte e a ciência são percebidas como áreas opostas de habilidade e de esforço humanos, com métodos e finalidades fundamentalmente diferentes. 
Com o início da revolução científica no século XVI, a concepção de ciências que perdura até hoje começou a se firmar. As relações sociais passaram a ser orientadas por uma racionalidade científica baseada na neutralidade e imparcialidade do conhecimento que acredita tudo explicar e tudo resolver. Tal modelo de racionalidade, aplicado no entendimento dos fenômenos das ciências naturais, especialmente a física e a química, tendo como principais características ser um modelo global, totalitário, nega a validade, ou o caráter racional, a todas as formas de conhecimento que não se pautarem pelos seus princípios epistemológicos e pelas suas regras metodológicas (Batista \& Bezerra, 2020). Desse modo, a arte, por não se pautar nos princípios de verdade e racionalidade objetiva da ciência nascente, passa a ocupar outro espaço na esfera do conhecimento já que aborda muito mais os aspectos subjetivos da apreciação e aprendizagem. Neste cenário emergente, conhecer significa quantificar; as qualidades intrínsecas do objeto são, por assim dizer, desqualificadas e, em seu lugar, passam a imperar as quantidades em que eventualmente se pode traduzir em números. Segundo descreve Ferreira:

A racionalidade científica moderna não se caracteriza por seu caráter contemplativo, ela se constitui como um saber que propõe uma intervenção na natureza com a intenção de dominá-la, transformá-la, agir sobre ela. Seus conceitos e pressupostos reproduzem uma concepção de mundo mecanicista, dualista, quantitativista e ordenadora. Ou seja: é um tipo de conhecimento que, ao interferir, modela, constrói a realidade, organiza segundo seus interesses, seus pressupostos e seus métodos, ela age no social, embora isso nem sempre fique explícito (Ferreira, 2010, p.265).

Nesse novo modelo científico a subjetividade e as emoções são problemas a serem evitados, a concepção de ciência e de conhecimento científico passa a ter como referência um modelo mecanicista, funcional, que reduz tudo o que há no universo a relações mecânicas de causa e efeito. Contudo, esse método empirista-indutivista tem sido fortemente questionado como método de produção do conhecimento mesmo nas disciplinas científicas como a química e a física.

Laudan (1993) ao considerar o conhecimento científico como instrumento de resolução de problemas sociais propôs que para avaliar os méritos das teorias científicas é mais importante perguntar se constituem soluções adequadas a problemas relevantes, do que perguntar se são "verdadeiras" ou se estão "validadas". Popper (1975) também critica a ausência de contextualização na produção e ensino da ciência moderna, e ainda apresenta a insustentabilidade do método puramente indutivista para um ensino de qualidade.

Vários teóricos (Mattos et al., 2020; Plazza, 2003; Ferreira, 2010) defendem a importância da associação da arte e da ciência na construção do conhecimento, eles propõem que a associação da arte no processo de ensino e aprendizagem de ciências é capaz de propiciar um propósito motivador ao ensino além de desenvolver os aspectos intelectuais, críticos e também sensitivos do aluno, nesse sentido Plazza, (2003) e Silva et. al (2007), trazem o debate da associação da ciência e da arte, apresentando-as não só como complemento teórico, mas como conhecimentos que se apropriam, especialmente quando envolvem desenvolvimento e aplicação de técnicas específicas, como a experimentação, ou outras atividades práticas. Orna, (2011) evidencia que:

Não há nada na arte que não tenha algo a ver com química. Todos os objetos de arte são substâncias materiais e, como tal, estão sujeitos às leis e às manipulações da química. Ao mesmo tempo, a química, em alguns casos limitados, também pode estar sujeita às manipulações do artista, sendo essas ciências essencialmente compostas. (Orna, 2011, p. 191).

A ciência e a arte são processos construídos pelo homem ao longo da história e estão estreitamente relacionados com as necessidades sociais de cada época. A visão de ciência imutável, inquestionável e infalível já é ultrapassada (Alves, 2020). A ciência não só se adapta ao momento histórico em que está presente, como também reflete os interesses e valores da sociedade que a pratica; assim como a arte, ela vai muito além do mero pensamento positivista, adentrando em campos onde os 
sentimentos, os interesses e a intuição assumem papel precursor no pensamento científico.

\subsection{Propósitos do ensino de ciências na BNCC}

Apesar da atual concepção de aprendizagem ativa, as práticas didáticas ainda manifestam características mecanicistas que vão de encontro à proposta didática atual. $\mathrm{O}$ aluno, visto como uma folha em branco apta a apenas receber e copiar as informações repassadas pelo professor, memorizando macetes e fórmulas, mas com dificuldade de relacionar os conhecimentos envolvidos na sua aprendizagem. Compreende-se hoje que o processo de ensino não é apenas a simples transmissão de conhecimentos, nem aprender é somente coletar informações. A aprendizagem é um processo complexo, neuropsiquicossocialcognitivo, isto é, integra aspectos cerebrais, psicológicos, cognitivos e sociais. Assim, não se podem desprezar nos processos de aprendizagem, as vivências e práticas culturais e sociais dos alunos (Nunes e Silveira, 2015).

De fato, o processo de educação é complexo e admite várias formas de aprendizagem. Enquanto a organização psíquica como a atenção, memória, sentimento, pensamento e emoção do aluno busca dar significado aos processos perceptivos, a sua estrutura cognitiva sistematiza a informação recebida de uma forma muito particular, e geralmente ao alcance das vivências e experiências pessoais do aluno (Mattos et al., 2020; Gómez Teran, 2011; Gardner, 1995; Gardener 1998). Nesta concepção epistemológica, o aluno assume papel ativo no processo de construção do conhecimento, desenvolvendo aspectos qualitativos da sua inteligência e capacidade de compreensão e expressão da realidade circundante. Como afirma Paulo Freire (1996, p. 47): "Ensinar não é transferir conhecimento, mas criar as possibilidades para a sua própria produção ou a sua construção".

Há, reconhecidamente, uma crise pelo prazer de estudar ciências. Isto se reflete nos baixos índices de procura por estes cursos na Universidades, e pelo baixíssimo desempenho do Brasil no Pisa, a exemplo da edição de 2018 em que 55\% dos nossos estudantes não apresentaram nível básico de conhecimento em ciências (Inep, 2019). Talvez um aspecto responsável por esta crise seja o fato de que a ciência e as práticas científicas são apresentadas aos alunos como um fazer genial, intuitivo e distante do verdadeiro método analítico, crítico e investigativo. Muitos alunos apreendem que para fazer ciência necessitariam não do exercício da vontade, da educação pela disciplina e pelo esforço pessoal, mas de uma genialidade que acreditam ser um dom, oriundo ou de uma dádiva divina ou de um fenômeno aleatório genético. Para eles, sem as qualidades que julgam inatas, restam apenas o apreciar e o memorizar esta ciência que, nesta concepção, distancia-se do fazer humano. Subordinam-se, assim, a ver o mundo por olhos estranhos aos seus, no caso, os dos professores ou os dos cientistas. Se há alguma admiração entre os estudantes pelos profissionais da ciência, há maior desinteresse entre eles pela carreira de pesquisador. Consequentemente, temos uma ausência de profissionais na área da docência das ciências naturais, o que alimenta um ciclo vicioso e uma perspectiva nada animadora para a ciência do nosso país. Com esta apatia no ensino de ciências, a Escola deixa de realizar um dos seus objetivos mais nobres que é o de alimentar a curiosidade dos alunos, propiciando-os situações formadoras e visões de mundo a partir do ambiente cultural que conhecem e vivenciam. O resultado é o desinteresse dos alunos com relação as disciplinas de ciências, notadamente Química e Física e o analfabetismo científico (Fourez, 2013; Soares, 2012; Sampaio et. al, 2002).

Como a educação é uma realização política, não se pode desconsiderar as intencionalidades e definições dos programas do Governo. O cenário educacional brasileiro, desde os anos de 1990, enfatizava a descentralização, a autonomia e a diversificação das experiências educativas formais no país. Com o intuito de sistematizar a gestão da educação e de afirmar os princípios educativos do educar e do cuidar, estimulava-se a formulação de documentos normativos que orientassem o ensino brasileiro a alcançar maiores índices de qualidade social da educação com base nos padrões mínimos de qualidade relacionados aos sistemas de avaliação de larga escala, particularmente ao Programa Internacional de Avaliação dos Estudantes 
(PISA) (Oliveira, 2011). Há para o sistema de ensino básico brasileiro, segundo Oliveira (2011), uma mudança significativa entre as marcas do governo FHC, presentes nos Parâmetros Curriculares Nacionais (PCN), que indicavam um ensino descentralizado, para uma política de regulação e centralização a partir de 2010, preconizado pela Lei de Diretrizes e Bases da educação Nacional (LDB) e, de forma mais intensa, no texto do Plano Nacional de Educação (PNE). Ainda segundo a autora, um marco desta mudança foi a instituição do IDEB, Índice de Desenvolvimento da Educação Básica, em 2007, baseado nos índices do PISA que, por sua vez, segue as recomendações da Organização para a Cooperação e Desenvolvimento Econômico (OCDE).

Proposto pelo Ministério da Educação, a Base Nacional Comum Curricular - BNCC (Brasil, 2018), é um documento normativo que define o conjunto orgânico e progressivo de saberes fundamentais que os alunos devem desenvolver ao longo das etapas e modalidades da educação básica, em conformidade com o que preceitua a Constituição Federal do Brasil, a Lei de Diretrizes e Bases da Educação Nacional (LDB, Lei no 9.394/1996) e o Plano Nacional de Educação vigente, PNE 2014/2024, sancionado pela Lei ${ }^{\circ}$ 13.005/2014. A BNCC foi homologada pela Portaria ${ }^{\circ} 1.570$ de 2017, com o objetivo de fundamentar os currículos educacionais, mas também de superar a fragmentação das políticas de educação, aspirando melhorar a qualidade da educação em nas diferentes regiões brasileiras, a partir de um ensino integral e contextualizado para os alunos.

De acordo com a BNCC (Brasil, 2018), a concepção de educação integral não se restringe a duração de uma carga horária, mas na condição de firmar valores e estimular ações que contribuam para a transformação da sociedade, tornando-a mais humana, socialmente justa e, também, voltada para a preservação da natureza (BRASIL, 2018). Um objetivo desta natureza não se alcança com as práticas tradicionais de ensino. É necessário ampliar a concepção de educação, transcender ao sentido que o senso comum the confere e considerar alternativas metodológicas capazes de promover uma formação mais plena do educando (Paro, 2010). O ensino contemporâneo requer vitalidade, dinamismo, participação, e isso não se alcança sem que as práticas pedagógicas considerem o educando em sua completude; sem que os conteúdos façam sentido e dialoguem com a realidade dos estudantes. A arte, como linguagem e expressão para o ensino de ciências, vem ao encontro da necessidade de despertar interesses e buscar novos rumos para educação e para a formação profissional docente, a partir da criação de instrumentos teóricos e estratégias pedagógicas que facilitem e potencializem o aprendizado de ciências. Aliás, as aproximações entre ambas, arte e ciência, são mais prováveis do que podem parecer à primeira vista (Reis et al, 2006; Ferreira, 2010).

O texto da BNCC (Brasil, 2018) para a área de Ciências da Natureza enfatiza um ensino contextualizado, formativo, interdisciplinar e objetivo, realçando, portanto, o protagonismo do aluno nas práticas pedagógicas. Para a efetivação dos projetos de vida e engajamento destes alunos nos mundos do trabalho e social, considera diferente itinerários formativos, ponderando a realidade local, os anseios da comunidade escolar e os recursos existentes, tanto humanos quanto materiais. Há competências e habilidades específicas a serem alcançadas que claramente transcendem ao aprendizado de seus conteúdos conceituais. Para que os alunos possam validar os conhecimentos científicos aprendidos em procedimentos úteis, advoga-se um olhar articulado entre diferentes saberes, uma abordagem social, histórica e cultural da ciência e da tecnologia, e situaçõesproblema de aprendizagens envolvendo, dentre outros temas, qualidade de vida, segurança, sustentabilidade, diversidade étnica e cultural (Brasil, 2018). Muitos desses aspectos podem ser explorados em parceria com a arte (Silveira, Quadros \& Silva, 2020; Silva et al., 2017). Um ensino pautado nos princípios da interdisciplinaridade, da dialética e da alfabetização científica, conceituada por Sasseron e Carvalho (2011) como a apropriação da cultura científica, e que concede ao aluno uma nova forma de ver o mundo e seus acontecimentos, possibilitando sua modificação e a transformação pessoal através da prática consciente, não dispensa as múltiplas linguagens disponíveis para a educação do ser.

Essas ideias exprimem direitos de aprendizagens que precisam ser assegurados aos alunos. Em uma conjuntura contemporânea em que a ciência e a tecnologia se destacam e definem mudanças e condições de vida, permanecer alheio ou às 
margens destes saberes, em um claro analfabetismo científico e tecnológico, representa não apenas um desastre pessoal, os alunos ficam impedidos de dialogar com o seu tempo e de se realizar enquanto indivíduos, como também desastre coletivo, já que a sociedade reflete o conjunto dos seus indivíduos (Batista \& Bezerra, 2020).

\subsection{Relações entre Ciências e Arte na BNCC.}

A BNCC para o ensino médio, assim como para os anos iniciais, se desdobra a partir do desenvolvimento de dez competências, que estão representadas de forma resumida no quadro a seguir:

Figura 1. Resumo das competências propostas na BNCC.

\section{Competências Exigidas na BNCC}

1. Valorizar os conhecimentos historicamente construidos.

2. Desenvolver e cultivar a curiosidade, a criatividade a reflexão e a análise critica.

3. Valorizar as diversas manifestaçöes artisticas e culturais.

4. Conhecer e utilizar diferentes linguagens, verbal, corporal, visual, sonora e digital

5. Utilizar e criar de maneira consciente as tecnologias digitais de informaçăo.

6. Valorizar a diversidade de saberes e vivências culturais entendendo as relaçōes próprias do mundo do trabalho.

7. Desenvolver a habilidade de argumentar com base em fatos, dados e informaçōes confiáveis.

8. Cuidar da saúde física e emocional

9. Exercitar a empatia, o diálogo, a resoluçăo de conflitos e a cooperaçăo,

10. Agir pessoal e coletivamente com autonomia, responsabilidade, flexibilidade, resiliência e determinação

Fonte: Extraído da Base Nacional Comum Curricular, de Ministério da Educação, Brasil (2018).

A percepção da arte como significativo componente curricular para a formação acadêmica e social do aluno (item 3 da figura 1) é um notável passo para a construção de uma sociedade não só existente, mais presente, criativa, construtiva e tolerante, que valoriza a comunicação, a expressão e arte. Ferraz e Fusari (2010), reconhecem a Arte como uma das mais eloquentes e inquietantes produções do homem. Para eles, a arte além de técnica, é lazer que integra o universo que nos circunda ao universo conceitual humano, e está estreitamente ligada ao pertencimento de humano.

A análise focaliza o capítulo 5.3 da BNCC (Brasil, 2018) destinada para o Ensino Médio, capítulo que aborda os objetivos e finalidades do ensino de ciências da natureza e suas tecnologias para os anos finais da educação básica. Buscamos analisar o que a Base Nacional Comum Curricular determina para o sistema de ensino vigente, quais as tendências educacionais, e se ela está em consonância com os outros documentos normativos propostos na pesquisa.

O foco da investigação centrou-se nos eixos que orientam os componentes curriculares de Ciências da Natureza e suas tecnologias para o ensino médio. Segundo as características de textos de comunicação em massa apresentadas por Bardin (2016), comprovamos que a BNCC possui texto característico de um documento direcionado para um público macro, sendo em sua maioria, contemplado com uma linguagem breve, clara, e que geralmente posiciona o leitor como parte importante para a efetivação das orientações fornecidas, características que tornam o texto atrativo para a leitura e de fácil compreensão. Contudo, esses textos nem sempre informam ao leitor dados relevantes sobre o embasamento teórico que fundamenta as ideias ali expressas, é comum que escritos dessa natureza possuam poucas ou nenhuma justificativa pautada na literatura que retifique as hipóteses ali descritas (Bardin, 2016).

O texto vislumbrado na BNCC participa da maioria dessas características, possui uma escrita clara, objetiva, porém um tanto reducionista, como a base é um documento destinado a um público, em sua maioria, culto, que são os profissionais da educação básica, explicações aligeiradas sobre temas relevantes pode abrir espaço para ambiguidades, equívocos na 
interpretação e questionamentos válidos sobre as reais finalidades do documento. Esse cenário propiciou uma série de críticas ao documento mesmo após sua homologação e a um recorrente esforço do governo para reparar a situação, elaborando, em conjunto com outros atores, sínteses de explicação do documento disponível nos endereços da internet das instituições educacionais que participaram da elaboração do documento, um site exclusivo para acesso do material disponível na internet, onde estão disponibilizados documentos de apoio jurídico e prático à BNCC.

O documento aborda temas muito relevantes para o ensino de ciências, mas como foi dito, sem aprofundar teoricamente os argumentos, o que exige dos docentes uma posição de pesquisador, aprendiz e principal avaliador da sua prática para que esta se alinhe com as perspectivas apontadas na BNCC para a educação atual. Outro ponto de reflexão relevante é o fato de que o documento não esclarece como, na prática, os objetivos propostos podem ser alcançados, quais as medidas governamentais deverão ser tomadas para o cumprimento dos objetivos, que em sua maioria são subjetivos ao aluno e ainda requerem assistência material e financeira para sua efetivação. A educação de um país é de responsabilidade social, coletiva e principalmente governamental, são essas entidades que devem administrar e fomentar o avanço da educação, nenhuma desses órgãos pode se eximir da parcela de responsabilidade para com a educação, e não se pode dissociar o emprego de recursos humanos e materiais com a melhora na qualidade da educação.

No documento não é possível identificar nenhum compromisso do estado com o fornecimento do suporte necessário para o desenvolvimento das propostas educacionais, mas se nota uma linguagem imperativa bastante presente ao enunciar os deveres da escola, dos alunos e dos profissionais da educação, de certa forma, nota-se um esquivamento do estado em relação à melhoria do ensino. O documento, nos parágrafos seguintes apresenta os objetivos do ensino médio e consequentemente do ensino de ciências da natureza que, como dito anteriormente, deve comprometer-se com a formação dos jovens para o enfrentamento seus desafios e dos desafios da contemporaneidade, buscando, para isso, uma da formação integral e cidadã (Brasil, 2018). Todavia formar os jovens com essas características certamente não será fácil tarefa, objetivos dessa magnitude requerem recursos humanos e financeiros que condigam com as expectativas do que foi objetivado, além de maior valorização do profissionalismo docente (Cury, Reis \& Zanardi, 2018; Silva, Alves Neto \& Vicente, 2015).

Segundo o documento, as competências nele propostas deverão reger a estrutura dos conteúdos que serão contemplados nos currículos de modo a preparar os estudantes para desenvolver e utilizar os conhecimentos obtidos em sala para argumentar, propor soluções, enfrentar desafios locais e globais, relativos à vida e ao ambiente.

Reconhecer o importante papel do professor como facilitador e motivador da aprendizagem ante as orientações trazidas na BNCC amplia a perspectiva educacional construída até então e volve nosso olhar para a completude da prática educativa. Só é possível alcançar uma educação de qualidade se compreendermos que esta envolve diversos personagens, cada um com seu papel significativo na construção e assimilação do saber. Santos e Amaral (2020) anuem a necessidade de os professores cultivarem o hábito de pesquisar, de inovar e proporcionar a partir de metodologias diferenciadas a aprendizagem dos alunos.

Certamente o profissional docente carece de uma formação voltada para a atual necessidade educacional do país, ter desde a formação acadêmica a perspectiva de um processo de ensino e aprendizagem formativo, que visa estimular a participação do educando em sociedade, atuando ativamente de maneira crítica e responsável, comprometido com a prática social consciente deve estar dentre as principais propostas de evolução dos currículos de formação dos professores (Pereira \& Cardoso, 2020).

\section{Conclusão}

Ao integrar a valorização da Arte como um objetivo de formação acadêmica, a BNCC reconhece que assim como outros componentes curriculares, a educação artística favorece o desenvolvimento intelectual do aluno, sendo muitas vezes 
capaz de propiciar a construção de conhecimentos significativos, por tanto, ela como uma das competências gerais da educação brasileira deve se desdobrar durante a trajetória proposta para as três etapas da Educação básica (Educação Infantil, Ensino Fundamental e Ensino Médio) como é apresentado no documento, a BNCC enfatiza seu compromisso com a educação integral, não apenas no sentido de aumentar a carga horária escolar, mas com o objetivo de formar e educar alunos em completude, o que implica compreender a complexidade e a não linearidade desse desenvolvimento, rompendo com visões reducionistas que privilegiam ou a dimensão intelectual (cognitiva) ou a dimensão afetiva (sensível).

O conceito de educação integral defendido no documento relaciona-se com a ideia de completude desenvolvida neste trabalho, defendida sob o ponto de vista da associação entre ciência e arte, razão e emoção, empírico e sensível, afinal, o ser humano é constituído por ambos os lados, e é utópico referir-se à formação integral do aluno, sem contemplar essas duas esferas do ser.

O texto da BNCC na área de ciências da natureza aborda a importância da disseminação dos conhecimentos científicos de maneira contextualizada prática e formativa, onde o aluno é o principal foco nas práticas didáticas e apresenta as finalidades e compromissos da educação científica para com os alunos do ensino médio, indicando que ao fim da etapa educacional os alunos deverão saber levantar ações práticas de julgamento e argumentação, além de instruir-se sobre o desenvolvimento e uso criterioso da ciência e das tecnologias dentro e fora da escola.

Esta perspectiva corrobora com os objetivos da educação atual que valida a importância da democratização dos conhecimentos científicos e tecnológicos, já que eles têm influenciado mudanças significativas no planeta e na vida humana. Nesse cenário, compreender as interações entre a ciência a tecnologia e a sociedade passa a ser uma necessidade, promover a cidadania é também possibilitar aos indivíduos educação que lhes permitam avaliar problemáticas, realizar escolhas conscientemente, realizar intervenções, baseadas na ciência de maneira responsável.

Essas ideias exprimem direitos atuais que precisam ser assegurados os alunos, numa conjuntura onde a ciência e a tecnologia influenciam as principais mudanças na vida não se enculturar desses saberes pode acarretar a um analfabetismo científico e tecnológico, que entre outras consequências pode impedir o íntegro exercer da cidadania. Dialogar as perspectivas da interdisciplinarização entre arte e ciência portanto, pode contribuir para o desenvolvimento de uma sociedade mais ativa e democrática.

A arte e a ciência fazem parte das nossas vidas e não apenas acompanham os acontecimentos do mundo, como, de ordinário, os definem. Na condição de saberes humanos, mantém relações entre si, de modo que um influencia o desenvolvimento do outro. O cientista, no laboratório, não dispensa sua criatividade e inspiração para criar seus instrumentos, técnicas e hipóteses, assim como o artista, em seu ateliê, acompanha o conhecimento científico para imprimir inovação e qualidade em suas obras. A educação, que desde o idealizador da pedagogia moderna, vive o desafio de ensinar tudo a todos, não pode manter-se alheia ao diálogo possível e permanente entre a ciência e arte. A arte fascina, estimula o raciocínio, a criatividade, desperta o interesse. Valores desejáveis em docentes e estudantes de qualquer nível. As diversas linguagens artísticas (poesia, prosa poética, romance, dança, teatro, cinema, pintura, história em quadrinho, jogos digitais, escultura, etc) se prestam para o ensino e, acreditamos, favorecem a aprendizagem. Há ainda muito por fazer para facilitar e favorecer este diálogo.

\section{Agradecimentos}

Os autores agradecem a CAPES pelo auxílio financeiro, a Universidade Federal do Maranhão e ao Programa de pós Graduação em Ensino de Ciências e Matemática pelo apoio no desenvolvimento deste trabalho. 


\section{Referências}

Abbagnano, N. (2007). Dicionário de Filosofia. 5ed. Ed. Martins Fontes.

Alves, T. R. de S. (2020). Percepções imagéticas nos livros didáticos de Química: investigando o assunto propriedades coligativas. Research, Society and Development, 9(7), e785974443. https://doi.org/10.33448/rsd-v9i7.4443

Argan, G. C. (1994). Preâmbulo ao estudo da História da Arte. In: FAGIOLO, M. Guia da História da Arte. Estampa.

Aranha. M. L. A. \& Martins, M. H. P. (2009). Filosofando: Introdução à Filosofia. 4ed. Moderna.

Aristóteles (2014). Ética a Nicômaco. Edipro.

Batista, W. M. \& Bezerra, C. W. B. (2020). O currículo e o ensino de ciências na educação básica: uma leitura da BNCC. Mens Agitat, 15, 90-102.

Bardin, L. (2016). Análise de Conteúdo. 70ed. Almedina Brasil.

Brasil (2018). Ministério da Educação. Base Nacional Comum Curricular. Brasília.

Cury, C. R. J., Reis, M. \& Zanardi, T. A. C. (2018). Base Nacional Comum Curricular: dilemas e perspectivas. Cortez.

Ferreira, F. R. (2010). Ciência e arte: investigações sobre identidades, diferenças e diálogos. Educação e Pesquisa, 36 (1), 261-280. https://doi.org/10.1590/S1517-97022010000100005

Ferraz, M. H. C. de T. \& Fusari, M. F. de R. (2010). Arte na educação escolar. 4ed. Cortez.

Fischer, E. (1987). A necessidade da arte. 9. ed. Guanabara Koogan.

Fourez, G. (2003). Crise no ensino de ciências. Investigações em Ensino de Ciências. v. 8 (2), pp 109-123.

Freire, P. (1996). Pedagogia da Autonomia: Saberes necessários à prática educativa. 35ed. Paz e Terra.

Gardner, H. (1998). Estruturas da Mente: A Teoria das Inteligências Múltiplas. Vozes.

Gardner, H. (1995). Inteligências Múltiplas: a Teoria na Prática. Porto Alegre, Artes Médicas.

Gómez, A. M. S. \& Terán, N. E. (2011). Dificuldades de Aprendizagem: Detecção e estratégias de ajuda. Grupo Cultural S. A.

Gurgel, I. \& Pietrocola, M. (2011). Uma discussão epistemológica sobre a imaginação científica: a construção do conhecimento através da visão de Albert Einstein. Revista Brasileira de Ensino de Física, v. 33 (1), 1602. DOI: https://doi.org/10.1590/S1806-11172011000100024.

Inep - Instituto Nacional de Estudos e Pesquisas Educacionais Anísio Teixeira. (2019). Pisa 2018 revela baixo desempenho escolar em leitura, matemática e ciências no Brasil. http://portal.inep.gov.br/artigo/-/asset_publisher/B4AQV9zFY7Bv/content/pisa-2018-revela-baixo-desempenho-escolar-em-leituramatematica-e-ciencias-no-brasil/21206.

Laudan, L. et. al. (1993) Mudança científica: modelos filosóficos e pesquisa histórica. Estudos Avançados [online], 7-89. DOI: https://doi.org/10.1590/S010340141993000300002

Nunes, A. I. B. L. \& Silveira, R. do N. (2015). Psicologia da Aprendizagem. 3ed. EdUECE.

Oliveira, D. A. (2011). Das políticas de governo à política de Estado: reflexões sobre a atual agenda educacional brasileira. Educação \& Sociedade, 32 (115), 323-337. DOI: http://www.scielo.br/pdf/es/v32n115/v32n115a05.pdf>.

Orna. M.V. (2011). Chemistry and Art: Ancient textiles and medieval manuscripts examined through chemistry. Revista Educación Química, 3(22), 191-197. México. DOI: https://doi.org/10.1016/S0187-893X(18)30133-2

Paro, V. H. (2010). Educação como Exercício do Poder: crítica ao senso comum em educação. Ed. Cortez.

Plaza, J. (2003). Arte/Ciência: uma consciência. ARS, 1 (1), 37-47. DOI: https://doi.org/10.1590/S1678-53202003000100004

Popper, K. R. (1975). Conhecimento objetivo. Ed. Universidade de São Paulo.

Reis, J. C., Guerra, A. \& Braga, M. (2006). Ciência e arte: relações improváveis? História, Ciências, Saúde-Manguinhos, 13, pp. 71-87. DOI: https://doi.org/10.1590/S0104-59702006000500005.

Sasseron, L. H. \& Carvalho, A. M. P. de. (2011). Alfabetização Científica: uma revisão bibliográfica. Investigações em Ensino de Ciências, 16 (1), 59-77, DOI: http://www.if.ufrgs.br/ienci/artigos/Artigo_ID254/v16_n1_a2011.pdf.

Sampaio, C. E. M. et al. Estatísticas dos professores no Brasil. Revista Brasileira de Estudos Pedagógicos, 83(203-205), 85-120. DOI: https://doi.org/10.24109/2176-6681.rbep.83i203-04-05.907

Santos, M. E. V. M. (2009) Ciência como cultura: paradigmas e implicações epistemológicas na educação científica escolar. Química Nova, 32 (2), $530-537$. DOI: https://doi.org/10.1590/S0100-40422009000200043.

Santos, F. R dos. \& Amaral, C. L. C. (2020) A química forense como tema contextualizador no ensino de química. Research, Society and Development, 9 (3), 1-15. DOI: http://dx.doi.org/10.33448/rsd-v9i3.2772. 
Research, Society and Development, v. 10, n. 13, e330101320942, 2021

(CC BY 4.0) | ISSN 2525-3409 | DOI: http://dx.doi.org/10.33448/rsd-v10i13.20942

Silva, A. M. T. B. et. al. (2017). Ciência e arte: um caminho de múltiplos encontros. Interacções, 13 (44), 7-18. DOI: https://doi.org/10.25755/int.4109.

Silva, I. L. F, Alves Neto, H. F. \& Vicente, D. V. (2015). A proposta da base nacional comum curricular e o debate entre 1988 e 2015. Ciências Sociais Unisinos, 51 (3), 330-342. DOI: https://doi.org/10.4013/csu.2015.51.3.10

Silveira, R. B. da, Quadros, I. P., \& Silva, C. L. L. P. V. da. (2020). Itinerários poéticos: o deslocamento pela cidade como propulsor de experiências estéticas no ensino de arte. Research, Society and Development, 9(7), e554974343. https://doi.org/10.33448/rsd-v9i7.4343.

Soares, E. C. (2012). O professor de química e a epistemologia da prática pedagógica: limites e desafios para a inovação. Tese de Doutorado. Pontifícia Universidade Católica do Rio Grande do Sul. Programa de Pós-Graduação em Educação. Rio Grande do Sul. DOI: http://hdl.handle.net/10923/2769.

Viereck, G. S. (1929) What Life Means to Einstein: An Interview. The Saturday Evening Post, October 26 , $17 . \quad$ DOI: https://www.saturdayeveningpost.com/wp-content/uploads/satevepost/what_life_means_to_einstein.pdf. 